\title{
Quality of Maternity Care and Client Satisfaction
}

Saraswoti Kumari Gautam Bhattarai ${ }^{1}$, Kanchan Gautam²

${ }^{1}$ Associate Professor, Karnali Academy of Health Sciences, School of Nursing and Midwifery, Jumla, Nepal

${ }^{2}$ Registered Nurse, Nepal Nursing Council, Kathmandu, Nepal

Corresponding Author:

Saraswoti Kumari Gautam Bhattarai

Email: saraswotigautam@gmail.com

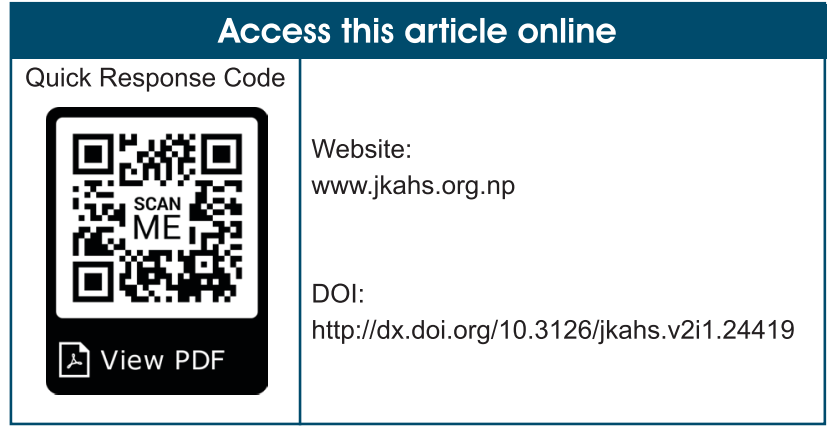

\begin{abstract}
Health service provided to pregnant women during antenatal, childbirth and postnatal period are essential for maternal and child health. Proper care during pregnancy, childbirth and postnatal period is important for the health of mother and baby. High maternal, infant and child morbidity and mortality demand improved healthcare which does not concern to coverage of health services alone. The health issues of pregnant women, mothers, infants and children need to be addressed with the attention to quality of care (QoC). The Nepal Health Sector Strategy (NHSS) also identifies equity and quality of care gaps as areas of concern for achieving the maternal health sustainable development goal (SDG) target. So this review aims to sensitize and draw the attention on quality of maternity care and client satisfaction to improve maternal and child health. For this article different studies related to quality of maternity care and satisfaction from care service received on maternity care are reviewed.
\end{abstract}

Keywords: Maternity care; Quality of Care; Satisfaction

\section{BACKGROUND}

Maternity care service includes the care during pregnancy, labour and childbirth and postpartum period $^{1}$. Quality of care is the extent to which health care services provided to individuals and patient populations improve desired health outcomes. In order to achieve this, health care must be safe, effective, timely, efficient, equitable and people-centered ${ }^{2}$. The quality of care for mother and baby around the time of birth provided in health facilities reflects the selection of health care interventions offered, the available physical infrastructure, human resources, knowledge, skills and capacity to deal with pregnancy and childbirth; normal physiological, social and cultural processes, and prompt life-saving interventions ${ }^{3}$. According to National Institute for Health and Care Excellence (NICE) quality standards are concise sets of prioritized statements designed to drive measurable quality improvements ${ }^{4}$.

The provision of good-quality maternal health services, leading to higher levels of client satisfaction, is an important goal of health institutions that provide maternal care. Maternity care service is improved since implementation of safe motherhood in Nepal ${ }^{1}$. Good 
quality of care during pregnancy, childbirth, and the postnatal period is important for the health of mothers and their babies 5 . Quality of care is an important but often neglected issue in safe motherhood programs ${ }^{6}$ that can be considered from the provider or user's perspective, and is differentiated into observed and perceived quality ${ }^{7,8}$. Though globally more women are giving childbirth in facilities, the quality of care and services available to these women is not uniform, nor is close to reaching the level of care ${ }^{9}$. Improving maternal and newborn health outcomes requires widespread utilization of high quality obstetric care. Attention to quality will be mainly important as women's expectations. The perceptions of quality differed significantly by types of health facility ${ }^{10}$. The higher level of facility readiness and service quality is needed to improve client satisfaction ${ }^{11}$.

\section{REVIEW AND DISCUSSION}

Quality for maternal and neonatal health has both clinical and non-clinical components, each measured in terms of structure (inputs), processes (actions), and outcomes (results) ${ }^{12}$. Women's choice of health facility was influenced by their perceptions of safety and staff attitudes. Barriers to the effective utilization of public maternity services were costs associated with the birth, staff attitudes and a lack of supportive care during labour and in the postpartum period. ${ }^{13}$. A hospital based cross sectional study done in Chitwan showed that $55.5 \%$ were satisfied with maternity services, $40.7 \%$ are highly satisfied and least (3.8\%) were unsatisfied. Satisfaction with the maternity care services was associated with the waiting time to receive the service and choosing service ${ }^{14}$.

A study done in central hill of Nepal (2014) reveals that the women's perception of quality of maternity service. Birth center was lowest on adequacy of medical equipment, health staff suited to women's health and adequacy of health staff', whereas public hospital was lowest with respect to adequacy of room, adequacy of water, environment clean, privacy and adequacy of information. Mean scores of total quality and sub-scales health facility and health care delivery for women attending private hospital were higher $(p<0.001)$ than those using birth center or public hospital. Mean score of the sub-scale interpersonal aspects for public hospital users was lower ( $\mathrm{p}<$ 0.001) than those delivered at private hospital and birth center. However, perception on interpersonal aspects by women using public hospital improved significantly after delivery $(p<0.001)^{10}$. Another facility based study done in Nepal showed that the respondents were most likely to suggest maintaining clean/hygienic health facilities ( $42 \%)$, increased bed provision (26\%), free services (24\%), more helpful behavior by health workers (18\%), and better privacy $(9 \%)$. Satisfaction with the information received showed a strong correlation with the politeness of staff, involvement in decision making, and overall satisfaction with the care received. Satisfaction with waiting time $(p=0.035)$, information received $(p=$ $0.02)$, and overall care in the maternity care $(<0.001)$ showed strong associations with willingness to return to facility ${ }^{15}$.

Likewise, a study done by Meheta in Nepal revealed that the clients who waited for less than $30 \mathrm{~min}$ before seeing a provider had higher satisfaction (54\%) than those who had to wait for longer than $60 \mathrm{~min}(9 \%)$. Clients who reached the facilities within $30 \mathrm{~min}$ had higher satisfaction compared to those who travelled for more than $30 \mathrm{~min}$. Clients who did not pay for the service and who did not report overcrowding at the health facility had higher satisfaction. Clients who received advice from health workers on danger signs for mothers and exclusive breastfeeding also had higher satisfaction. Clients who had an opportunity to ask questions to the health providers had higher satisfaction compared with those did not have that opportunity ${ }^{16}$. Similar study done in Kenya and Namibia showed that the better structural quality did not translate to better service delivery process or greater client satisfaction. Long waiting time was a common problem and generally more serious in hospitals and health centers than in clinics and smaller facilities; it was consistently associated with lower client satisfaction. It also indicates that the provider's technical preparedness may not be sufficient to provide good-quality services and to ensure client satisfaction ${ }^{17}$. Furthermore, a study done in Nepal 
showed that the most of the client were satisfied with care received at the facility $(86 \%)$, provider's skills $(85 \%)$, politeness of staff $(83 \%)$, waiting time $(80 \%)$, involvement in decision making (77\%), cleanliness $(70 \%)$, information received (69\%), and assured confidentiality (67\%). Satisfaction with information received showed a strong correlation with politeness of staff, involvement in decision making, and satisfaction about care at facility. Likewise, satisfaction with skill of service provider also showed a strong correlation with politeness of staff and satisfaction with care received. Furthermore, a strong correlation was observed between future use of services and the overall care received at the facility ${ }^{15}$. Lastly, health facilities need to have an adequate supply of diagnostic items, medicine and commodities, and guidelines. To improve the level of client satisfaction, facilities should adopt appropriate mechanisms to improve the service delivery process and to provide an adequate level of counseling to the clients, creating an enabling environment for clients to discuss their problems and concerns and to receive adequate explanations from providers ${ }^{11}$.

\section{CONCLUSION}

Availability of adequate providers, medicines, equipment and supplies, referral systems, hygiene, respectful behavior, better communication and more supportive care is important to improve the quality of maternity services. Health systems should focus on physical and human resources, increasing supplies and infrastructure. Sensitizing all facility staff on respectful behavior, therapeutic communication and supportive care is a critical element. Facility managers and providers should thus enhance the scope and appropriateness of maternity care services provided and delivered in a humane and respectful manner to every woman.

\section{REFERENCES}

1. Ministry of Health of Nepal; New ERA, ; ICF. Nepal Demographic and Health Survey 2016: Key Indicators. Kathmandu, Nepal. Nepal: Ministry of Health. 2017.
2. WHO. Standards for improving quality of maternal and newborn care in health facilities 2016.

3. WHO. Standards and Quality Statements for Facility Based Maternal and Newborn Care Around the Time of Child-Birth: 2015.

4. National Institute for Health and Care Excellence (NICE). Standards and Indicators. Quality Standards, London: NICE. 2015.

5. World Health Organization. Pregnancy, Childbirth, Postpartum and Newborn Care: A guide for essential practice. Integrated Management of Pregnancy and Childbirth:. World Health Organization. 2006.

6. Van den Broek NG. Quality of care for maternal and newborn Health : The Neglected Agenda. BJOG. 2009 ;116, 18-21

7. Baltussen R YeY, Haddad S, Sauerborn R. Perceived quality of care of Primary health Care Service Burkino Faso. Health Policy Plan. 2002:17(1), 42-48.

8. Hulton L, Matthews Z, Stones R. Applying a framework for assessing the Quality Health service in India. Social Science Med. 2007: 64(10), 2083-2095.

9. Diamond-Smith N, Sudhinaraset M, Montagu D. Clinical and perceived quality of care for maternal, neonatal and antenatal care in Kenya and Namibia: the service provision assessment. Reproductive Health. 2016: 13(92). doi:DOI 10.1186/s12978-016-0208-y

10. Karkee R, Lee A, Pokharel P. Women's perception of quality of maternity services: a longitudinal survey in Nepal. BMC Pregnancy and Childbirth. 2014: 14(45).

11. Acharya S, Sharma S, Dulal B, Aryal K. Quality of Care and Client Satisfaction with Maternal Health Services in Nepal: Further Analysis of the2015 Nepal Health Facility Survey. Kathmandu, Nepal: Ministry of Health and Population,ICF, Rockville, Maryland, USA. July 2018. 
12. Donabedian A. The quality of care: How can it be assessed? JAMA. 1988;260(12):1743-8

13. Ith $\mathrm{P}$, Dawson A, Homer C. Women's perspective of maternity care in Cambodia. Women and Birth . 2013: 26 , 71-75.

14. Sapkota D, Sapkota MA, Shrestha B. Mother's Satisfactionon Maternity Care Service in Bharatpur Hospital. International Journal of Scientific and Research Publications. 2018, September) 8(9). doi:DOI: 10.29322/ IJSRP.8.9.2018.p8196

15. Paudel Y, Mehata S, Paudel D, Dariang M, Aryal K, Poude P, Barnett S. Women's Satisfaction of Maternity Care in Nepal and Its Correlation with Intended Future Utilization. International Journal of Reproductive Medicine. 2015. doi:http://dx.doi.org/10.1155/2015/78305
16. Mehata S, Paudel U, Dariang M, Aryal K, Paudel S. Factors determining satisfaction among facility-based maternity clients in Nepal. BMC Pregnancy and Childbirth.2017: 17(319). doi:DOI 10.1186/s12884-017-1532-0

17. Do M, Wang W, Hembling J, Ametepi P. Quality of antenatal care and client satisfaction in Kenya and Namibia. International Journal for Quality in Health Care. 2017: 29(2), 183193. doi:doi: 10.1093/intqhe/mzx001

\section{How to cite this article?}

Bhattarai SKG, Gautam K. Quality of Maternity Care and Client Satisfaction. Journal of Karnali Academy of Health Sciences. 2019;2(1):73-76

Conflict of Interest: None Source of Support: None 